\title{
Pleomorphic adenoma of nasal septum: A case report
}

\author{
Paudyal $\mathrm{P}^{1}$, Pande $\mathrm{K}^{1}$, Pradhan $\mathrm{A}^{1}$, Shah $\mathrm{R}^{1}$, Upadhyaya $\mathrm{P}^{1}$, Thapa $\mathrm{S}^{2}$ \\ ${ }^{\prime}$ Department of Pathology, BP Koirala Institute of Health Sciences, Dharan, Nepal. \\ ${ }^{2}$ Department of Otorhinolaryngology and Maxillofacial Surgery, BP Koirala Institute of Health Sciences, Dharan, Nepal.
}

\section{Keywords:}

Nasal obstruction;

papilloma;

Nasal septum;

Pleomorphic adenoma

\begin{abstract}
Pleomorphic adenomas are the most common benign tumor of the major salivary glands. Other rare sites for the occurrence of pleomorphic adenoma have been described in the larynx, pharynx, nasal cavity, lacrimal glands and trachea. We report here a case of intranasal pleomorphic adenoma arising from the nasal septum causing nasal obstruction which was clinically diagnosed as papilloma. Histopathology confirmed the diagnosis of pleomorphic adenoma.
\end{abstract}

\section{INTRODUCTION}

Pleomorphic adenoma (PA) is the most common benign mixed salivary gland tumor occurring in major salivary glands. ${ }^{1}$ Salivary gland tumours constitute about $3 \%$ of all neoplasms. The majority of these tumours are benign and about $70 \%$ are Pleomorphic adenoma. ${ }^{2}$ In rare instances can occur in the respiratory tract mainly in the nasal cavity, maxillary sinuses, nasopharynx and rarely oropharynx, hypopharynx and laynx. ${ }^{3}$

Intranasal (nasal septum) PAs are unusual and may be misdiagnosed because they have greater myoepithelial cellularity and fewer myxoid stroma compared to those

\section{Correspondence:}

Dr. Punam Paudyal, MBBS, MD

Department of Pathology, BP Koirala Institute of Health Sciences,

Dharan, Nepal.

Emai: punam.paudyal@bpkihs.edu elsewhere. 3 They typically grow slowly and prone to have recurrence even after surgical resection. ${ }^{4}$

\section{CASE REPORT}

A 64 years old female presented to the outpatient department of ENT with complaints of right nasal obstruction for the last six months duration. On examination, single pinkish fleshy mass was observed which was attached to the septum and which did not shrink upon the usage of decongestant. With clinical diagnosis of nasal septum papilloma, submucosal resection was done under general anaesthesia and excised mass was sent for histopathological examination. We received a single nodular gray white, soft tissue measuring $2.5 \times 2.0 \times 1.2 \mathrm{~cm}$. Cut surface was solid, gray and white with focal brownish discoloration. Microscopy revealed respiratory lining epithelium and 


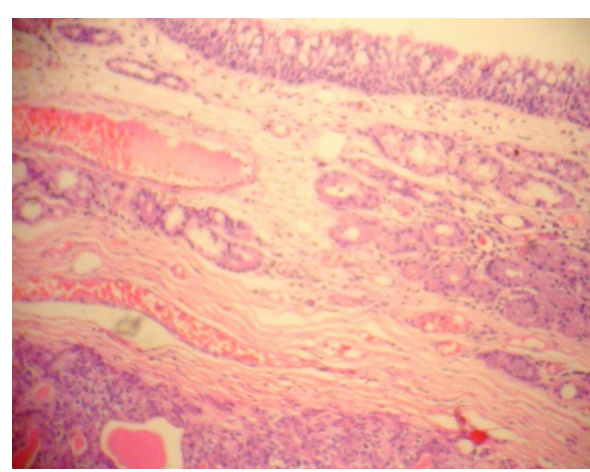

Figure 1: Section revealing respiratory lining epithelium and subepithelium containing mixed tumor (HE stain, x100).

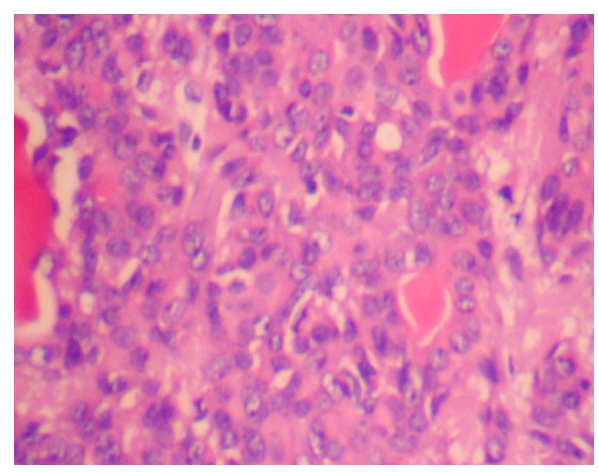

Figure 3: Section revealing ducts and tubules containing eosinophilic secretion and lined by epithelial and myoepithelial cells (HE stain, x40).

subepithelium containing mixed tumor (fig.1). The tumor reveals epithelial, myoepithelial and mesenchymal component having myxoid, mucoid and chondroid areas (fig. 2). Epithelial components are seen in the form of ducts and tubules containing eosinophilic secretion and lined by cuboidal and myoepithelial cells. (fig. 3)

\section{DISCUSSION}

The most common tumor of the major salivary glands are pleomorphic adenoma, but in rare instances, they can occur in the respiratory tract (via minor salivary glands). ${ }^{5}$ In the upper respiratory tract, the most favored site of origin is the nasal cavity, followed by the maxillary sinus and the nasopharynx. ${ }^{6}$

The first reported case in the literature of a PA of the nasal cavity was in 1929. ${ }^{7}$ Larger studies of intranasal pleomorphic adenoma includes 40 cases reported by Compagno and Wong and 59 cases reported by Wakami et al. ${ }^{8,9}$ The majority of cases occur between the third to sixth decades of life and are seen more frequently in women. ${ }^{10}$ This finding is similar to our study. The main presenting feature is painless, unilateral nasal obstruction, a mass within nasal cavity and epistaxis..$^{10}$ In our study also patient presented to the outpatient department with the complaint of

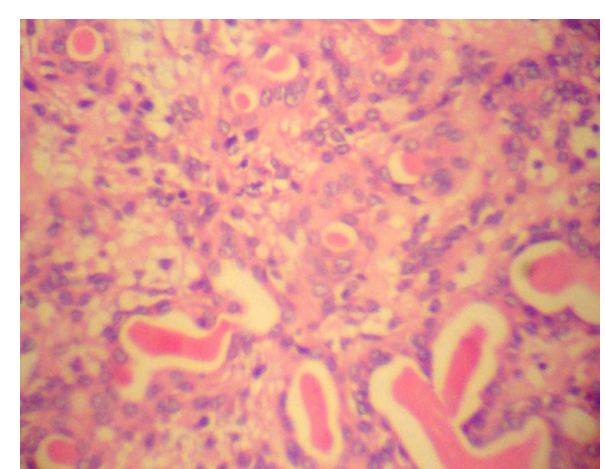

Figure 2: Section reveals stromal and myxoid areas along with myoepithelial cells and few ducts (HE stain, x40)

unilateral nasal obstruction.

Histologically, Pleomorphic adenomas of the nasal cavity contain both mesenchymal and epithelial components. Although similar to tumors commonly seen in the major salivary glands, the histopathologic features of mixed tumors of the nasal cavity may resemble aggressive epithelial tumours because of the high cellularity and lack of a stromal component. ${ }^{11}$ This can lead to misdiagnosis as a carcinoma. Remote chance of misdiagnosis is present because of greater myoepithelial cellularity and fewer myxoid stromas as compared to that elsewhere. ${ }^{11}$ Occasionally, small acini or duct like structures filled with secretions are present along the perimeters of the more cellular foci. ${ }^{11}$

A neoplasm originating from the nasal septum has a higher risk of malignancy compared to other sites in the nose. ${ }^{12}$ Occasionally, pleomorphic adenoma can behave in a malignant fashion, the most common variant being carcinoma ex pleomorphic adenoma which has potential to metastasise. ${ }^{12}$

\section{CONCLUSION}

In case of any unilateral mass presenting with nasal obstruction, pleomorphic adenoma should be considered in the differential diagnosis. Tumor of the nasal septum has a higher risk of malignancy and potential for tumor recurrence, so, long term follow up and careful examination of the nose (endoscopic) are necessary.

\section{ACKNOWLEDGEMENT}

We would like to acknowledge the contributions of all the faculties, junior residents and technical staffs of department of Pathology, BPKIHS for their help in preparing manuscript. We are very grateful to Prof Dr Smriti Karki and Prof Dr Arvind Kumar Sinha for their constant support. 


\section{REFERENCES}

1. Jassar P, Staffored N, Macdonald A. Pleomorphic adenoma of the nasal septum. J Laryngol Otol 1999;113:483-5. Crossref

2. Rosai J, editor. Rosai and Ackerman's surgical pathology, 9th ed. St. Louis, MO: Mosby; 2004.3136pp.

3. Gana P, Masterson L: Pleomorphic adenoma of the nasal septum: a case report. Journal of medical case reports 2008;2:349. Crossref

4. Gill BS,Rekhi BM.Pleomorphic adenoma of the nose-A case report. Indian J Otolaryngol 1968;20:132-4.

5. Shaheen $\mathrm{OH}$. Benign salivary gland tumours: Scott Brown's Otolaryngology, 6th edn, Oxford, Butterworth-Heinemann;1997. pp 5.

6. Suzuki, K., Moribe, K., Baba, S. A rare case of pleomorphic adenoma of the lateral wall of the nasal cavity with special reference of statistical observation of pleomorphic adenoma of the nasal cavity in Japan. Oto-Rhino-Laryngological Society of Japan. 1990;93:740-45. Crossref
7. Denker A, Kehler O: Handus der Hals. Nasen Ohrenheilkunde. $1929 ; 5: 202$

8. Compagno J, Wong RT. Intranasal mixed tumors (pleomorphic adenomas): A clinicopathologic study of 40 cases. Am J Clin Pathol 1977;68:213-8. Crossref

9. Wakami S, Muraoka M, Nakai Y. Two cases of pleomorphic adenoma of the nasal cavity. Nippon Jibiinkoka Gakkai Kaiho 1996; 99:38-45. Crossref

10. Matoori K, Takano H, Nakano K: Pleomorphic adenoma of the nasal septum: MR features. Am J Neuroradiol 1948;10:21.

11. Haberman RS, Stanley DE. Pleomorphic adenoma of the nasal septum. Otolaryngol Head Neck Surg 1989;100:610-2. Crossref

12. Krolls SO, Boyers RC. Mixed tumors of salivary glands. Long-term follow-up. Cancer 1972;30:276-81. Crossref 